\title{
Open-access endoscopy service for general practitioners
}

\author{
G HOLDSTOCK, M WISEMAN, C A LOEHRY
}

\section{Introduction}

Endoscopy of the upper gastrointestinal tract in experienced hands has definite advantages over conventional barium-meal examination. ${ }^{12}$ It is a more accurate diagnostic tool and lesions can be directly inspected and biopsy specimens taken. Most centres have endoscopy units, and as the number of patients referred for investigation increases methods for rationalising and reducing the total work load should be evaluated. In most centres endoscopy is available only to hospital practitioners, and all patients who undergo it are carefully scrutinised by them. To avoid delay an instant endoscopy service has been established, ${ }^{3}$ whereby patients undergo their initial consultation and endoscopy on the same occasion. The logical progression from this is a direct-referral general-practitioner endoscopy service that avoids clinic referral entirely. This has already happened with barium-meal studies.

We have reported the early results of a general-practitioner endoscopy service 4 and compared the endoscopic and radiological findings. We decided to assess critically the impact of the introduction of this general-practitioner service over three years and to compare patients referred by general practitioners with those referred from hospital outpatient departments.

\section{Patients and methods}

In 1974 all the general practitioners in the area were informed of the availability of the direct-referral service. No guidelines were given about patient selection, since direct-referral barium-meal examinations had been available for 10 years. Patients were referred by a standard form and were admitted to a day ward attached to the endoscopy unit. They were sedated with intravenous diazepam, and endoscopies were performed by a consultant physician, two general-practice clinical assistants, and a medical registrar. A report of the findings was sent to the referring general practitioner, who was responsible for any further action unless a cancer or gastric ulcer was found, when patients were followed in hospital clinics.

In all patients attending for endoscopy the reason for referral, the duration of symptoms and drug treatment, and the number who had 
undergone a barium-meal examination in the past five years were recorded. All 99 general practitioners in the area were sent questionnaires to assess their reactions to the introduction of the service.

\section{Results}

To simplify assessment we divided patients into groups attending during six-month periods and did not include patients who underwent repeat investigation or those referred as inpatients. Over the three years from January 1975 to December 19771077 and 728 patients were referred for endoscopy by general practitioners and from outpatient departments respectively. Table I shows the reason for referral of patients attending from general practices and outpatient departments over the first and last six-month periods of the study. There was no significant difference in the duration of symptoms between the two groups, and on average the symptoms had been present for one year. Of the patients referred by general practitioners, $129(12 \%)$ had undergone prior barium-meal examination compared with $182(25 \%)$ of those referred from hospital. Out of a sample group of $\mathbf{4 0 0}$ patients with dyspepsia, 200 of those referred by general practitioners were taking antacid compared with 300 of those attending from outpatient departments. The endoscopic findings in both referral groups are shown in table II, and the changing pattern in endoscopic diagnosis in the two groups over the three-year period in fig 1 .

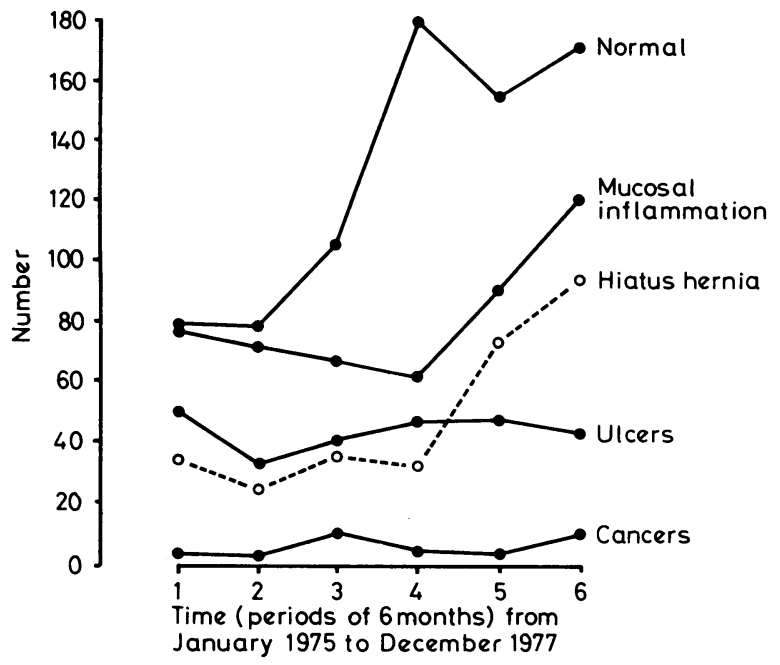

FIG 1 - Changing pattern of endoscopic diagnosis during Jan 1975-Dec 1977, divided into groups attending over six-month periods.

TABLE I-Reasons for referral for endoscopy in patients attending from general practices and outpatient departments, fanuary-fune 1975 and fuly-December 1977

\begin{tabular}{|c|c|c|c|c|c|c|}
\hline & Dyspepsia & $\begin{array}{c}\text { Weight } \\
\text { loss }\end{array}$ & Anaemia & Dysphagia & Other & Total \\
\hline \multicolumn{7}{|c|}{ Outpatient department } \\
\hline $\begin{array}{l}\text { Jan-June } 1975 \\
\text { July-Dec } 1977\end{array}$ & $\begin{array}{r}56 \\
103\end{array}$ & $\begin{array}{r}20 \\
5\end{array}$ & $\begin{array}{l}22 \\
17\end{array}$ & $\begin{array}{l}5 \\
6\end{array}$ & $\begin{array}{l}3 \\
4\end{array}$ & $\begin{array}{l}106 \\
135\end{array}$ \\
\hline \multicolumn{7}{|c|}{ General-practice referrals } \\
\hline $\begin{array}{l}\text { Jan-June } 1975 \\
\text { July-Dec } 1977\end{array}$ & $\begin{array}{r}67 \\
225\end{array}$ & $\begin{array}{l}10 \\
15\end{array}$ & $\begin{array}{l}11 \\
14\end{array}$ & $\begin{array}{l}4 \\
5\end{array}$ & $\begin{array}{r}14 \\
1\end{array}$ & $\begin{array}{l}106 \\
260\end{array}$ \\
\hline
\end{tabular}

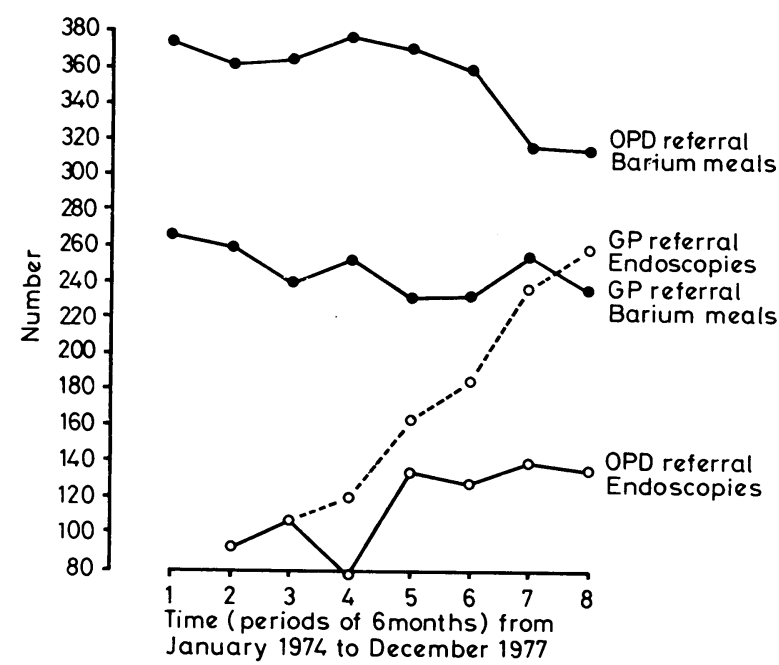

FIG 2-Total number of patients referred for endoscopies and barium studies by general practitioners (GP) and from outpatient departments (OPD), Jan 1974-Dec 1977.

Over the three years 190 of the patients referred by general practitioners $(17.6 \%)$ and 103 of those referred from hospital $(14 \%)$ were found to have either ulcers or cancers. Considering patients with gastric carcinomas separately, we found no difference between the two groups in duration of symptoms before endoscopy, histological staging of the disease, or prognosis. One carcinoma in situ was found in each referral group. The numbers were too small for statistical analysis. The overall pick-up rate for ulcers and cancers fell during the three years from $25 \%$ to $13 \%$. Pathology of less importance-for example, mucosal inflammation and hiatus hernia-was found in $45 \%$ of patients in both groups.

Fig 2 shows the number of patients referred for barium-meal examinations and endoscopies by general practitioners and from hospital clinics during January 1974 to December 1977. On average each general practitioner in the area referred 11 patients, but four referred over 100 . Of the 99 general practitioners in the area who were sent the questionnaire, 90 replied, and five of these were not aware of the service. All the remaining 85 general practitioners thought that the service was useful and 70 thought that it resulted in an appreciable reduction in clinic referrals. Forty-six used endoscopy instead of barium studies, 34 used both, and five used endoscopy only if the result of the barium study was abnormal. Sixty-six thought that even a negative endoscopy report altered patients' management.

\section{Discussion}

Our findings show that an open endoscopy service is relatively easy to establish and run. Although this service is expensive, most units already have many of the required facilities. The only additional staff we have recruited are two general-practice clinical assistants, who work one session each on alternate weeks.

By making endoscopy more easily available we attracted additional patients, most of whom had dyspepsia. The number of patients referred with more sinister symptoms did not increase, and therefore it was not surprising that the number of cases of ulcers and cancers diagnosed did not increase. The reason for this might have been that the lesions were being diagnosed earlier, though our results suggest that this is unlikely, since the duration of symptoms before endoscopy was not appreciably

TABLE II-Classification of patients referred by general practitioners and hospital outpatient departments during fanuary 1975 to December 1977 , according to endoscopic diagnosis

\begin{tabular}{|c|c|c|c|c|c|c|c|c|c|}
\hline Referral & Total & Cancers & Ulcers & Duodenitis & Gastritis & Oesophagitis & Hiatus hernia & $\begin{array}{l}\text { Hiatus hernia } \\
\text { and oesophagitis }\end{array}$ & Normal \\
\hline $\begin{array}{l}\text { General practitioners } \\
\text { Outpatient department }\end{array}$ & $\begin{array}{r}1077 \\
728\end{array}$ & $\begin{array}{l}14 \\
23\end{array}$ & $\begin{array}{r}176 \\
80\end{array}$ & $\begin{array}{r}100 \\
57\end{array}$ & $\begin{array}{r}115 \\
90\end{array}$ & $\begin{array}{r}108 \\
51\end{array}$ & $\begin{array}{r}100 \\
90\end{array}$ & $\begin{array}{l}62 \\
39\end{array}$ & $\begin{array}{l}464 \\
375\end{array}$ \\
\hline Total & 1805 & 37 & 256 & 157 & 205 & 159 & 190 & 101 & 839 \\
\hline
\end{tabular}


different in patients with cancer or in those with less serious disease. Fewer of the patients referred by general practitioners were taking antacids, which presumably resulted from easier access to endoscopy.

Although we hoped that introducing the general-practitioner service might reduce the work load on the department of radiology and number of hospital clinic referrals for endoscopy this was not the case. Since about half of the general practitioners used gastroscopy instead of barium studies, it is disappointing that the number of barium-meal examinations performed did not fall, and apparently the introduction of the generalpractitioner service has resulted in referrals of patients who had escaped investigation of the upper gastrointestinal tract. Certainly few of these patients had previously undergone barium-meal examination or indeed any other type of investigation before endoscopy.

Our results might be interpreted as suggesting that few if any of the additional patients that we attracted had clinically important disease, and that those who did would have attended in any case. Despite increasing the number of endoscopies in each six-month period, the number of gastric cancers diagnosed did not increase, which suggests that screening for gastric cancer in Britain by making endoscopy more accessible is not likely to be worth while, although it has been advocated. ${ }^{5}$

It is difficult to justify the increasing numbers of endoscopies purely on the basis of an increased pick-up rate of less important disease such as hiatus hernia or mucosal inflammation. These conditions may not be the cause of the patients' symptoms and the endoscopic diagnosis depends largely on observer variation. Also, since the treatment for these conditions is basically symptomatic, it is unlikely to be influenced by endoscopic diagnosis. The value of negative endoscopic findings cannot be adequately assessed, though the patient's anxiety may be relieved and management simplified. Although most general practitioners thought that clinic referral was reduced, we have no objective evidence of this. The number of patients referred for endoscopy from hospital clinics did not decrease.
During the three-year study, as the number of patients referred increased, so the waiting list lengthened. Towards the end of the study period the waiting list was as long as two to three months. Some more urgent cases might therefore have suffered unnecessary delay, and this waiting list might have negated one theoretical benefit of the general-practitioner service. If other units intend to set up a similar service we suggest that the number performed should be limited, perhaps by establishing stricter criteria for patient referral by general practitioners or by careful scrutiny of patients by the endoscopist, although this defeats the object of a general-practitioner service, since they are still screened by hospital clinics.

We think that introducing a general-practitioner directreferral endoscopy service along the lines that we have described results in too many endoscopies being performed for too little objective benefit. This is not a criticism of the general practitioners who have referred patients. Their pick-up rate of disease is slightly better than that of hospital doctors and the documented decrease in diagnostic yield resulting from increasing the number of endoscopies performed is also applicable to hospital practice. One way of avoiding this problem would be to make a general-practitioner service available to patients aged over 50, in whom examination may be more rewarding, but to have stricter criteria for younger patients. This could be achieved either by demanding a barium-meal examination before endoscopy or by insisting on clinic referral.

\section{References}

${ }^{1}$ Beales, J S M, and Cotton, P B, in Advanced Medicine Symposium 11, p 19. Tunbridge Wells, Pitman Medical, 1975.

${ }^{2}$ Cotton, P B, in Advanced Medicine Symposium 13, p 359. Tunbridge Wells, Pitman Medical, 1977.

${ }^{3}$ Beans, A K, La Brooy, S, and Misiewicz, J J, Gut, 1978, 19, 447.

4 Fisher, A, et al, British Medical fournal, 1977, 2, 1199.

${ }^{5}$ Lancet, 1978, 1, 1023.

(Accepted 15 November 1978)
Many proprietary cough medicines contain an antihistamine, which probably exerts an antitussive effect by acting as a central sedative. The principal active agent in Benylin is diphenhydramine, one of the ethanolamine group of antihistamines. Drugs in this group possess definite anticholinergic activity, and are particularly apt to produce central nervous system effects. ${ }^{1}$ In therapeutic doses central depression is common; about half of patients taking diphenhydramine experience sedation. Central stimulation, however, is occasionally encountered with conventional doses. Thus patients may become restless, nervous, and unable to sleep. Central excitation-sometimes leading to convulsions-is also a prominent feature of overdosage with antihistamines. Large doses of diphenhydramine can cause psychotic behaviour, with delusions and visual hallucinations. ${ }^{2}$ Individuals who consume large quantities of Benylin are therefore likely to experience changes in mood or feeling that may lead to abuse of the medicine. Although there have been no British reports of Benylin abuse, abuse of diphenhydramine preparations, including proprietary motion-sickness remedies, has been reported in Scandinavia. Ingestion of up to $200 \mathrm{ml}$ doses of a diphenhydramine-based cough syrup produced psychotic episodes, with disorientation, motor restlessness, and visual and auditory hallucinations. ${ }^{3}$ Chronic abuse led to dependence, with patients showing physical signs of parasympathetic blockade, and abrupt withdrawal produced abstinence symptoms. A recent report from the USA described a related problem with anticholinergic drugs prescribed for extrapyramidal symptoms secondary to phenothiazine treatment. ${ }^{4}$ Patients were found to be abusing benzhexol (Artane) and benztropine (Cogentin) for their euphoriant and hallucinogenic effects. Whether Benylin can be said to be addictive depends on what we mean by addiction. Classically, the term has been used to describe a pattern of compulsive drug use characterised by physical dependence, tolerance, and a withdrawal syndrome (for instance, opiate addiction). Benylin is not addictive in this sense. Nevertheless, with the current widespread use and abuse of psychotropic drugs, the term addiction is of limited value, and can be considered simply as an extreme on a continuum of drug abuse. Many drugs present considerable problems of dependence and compulsive use without meeting the strict definition of addiction, and anticholinergics such as diphenhydramine should be included in this group.

\footnotetext{
${ }^{1}$ Douglas, W W, in The Pharmacological Basis of Therapeutics, ed L 'S Goodman and A Gilman, 5th edn, p 606. New York, Macmillan, 1975.

${ }^{2}$ Nigro, S A, Journal of the American Medical Association, 1968, 203, 139.

- Rubinstein, J S, New England fournal of Medicine, 1978, 299, 834.
}

The use of idoxuridine is effective in herpes zoster. Two elderly patients had such a clearly anatomical distribution of zoster-like pain that there was no doubt that this was the cause, but there has been no eruption. Would idoxuridine help this pain? (The makers' instructions are to use it only on the vesicles or erythematous areas.)

Idoxuridine is effective only against the cutaneous lesions of herpes zoster if it is applied in DMSO (dimethyl sulphoxide to $100 \%$ ). Hence the manufacturers' instruction that this preparation should be applied only to erythematous areas or to vesicles. The intense pain that accompanies or follows the appearance of skin lesions is almost certainly due to the inflammatory changes caused by the presence of the varicella virus in the corresponding dorsal root ganglia. Such changes may possibly occur in the absence of obvious skin lesions. Whether varicella virus within ganglia is responsive to systemic treatment with herpes zoster immunoglobulin ${ }^{1}$ or with adenine arabinoside treatment ${ }^{2}$ has been reviewed fairly recently. These two patients are unlikely to benefit from any skin application.

Unduman, S A, et al, fournal of the American Medical Association, 1975, 234, 1049. Whitley, J R, et al, New England fournal of Medicine, 1976, 294, 1193. 